\title{
Proposta de design de sequência pictórica de procedimento para uso do coletor menstrual ${ }^{1}$
}

Design proposal of procedural pictorial sequence for the use of menstrual cup

\author{
CARVALHO, Daniele de O.; Graduanda; Universidade Federal do Paraná \\ acarvalhodani@gmail.com \\ LOPES, Amanda K.; Graduada; Universidade Federal do Paraná \\ amandalopesklod@gmail.com \\ RATI, Bianca M.; Graduada, Universidade Federal do Paraná \\ biancamrati@gmail.com \\ SPINILLO, Carla G.; PhD; Universidade Federal do Paraná \\ cgspin@gmail.com
}

\section{Resumo}

O coletor menstrual é uma alternativa aos absorventes convencionais que vem sido adotada por muitas brasileiras. Seu uso traz vantagens econômicas, ambientais e relacionadas à saúde e empoderamento feminino. Neste artigo apresenta-se o desenvolvimento de uma sequência pictórica de procedimento (SPP) para o uso do coletor menstrual, realizado através de pesquisa sobre o produto e análise gráfica de similares. A proposta de design foi avaliada junto a potenciais usuárias e os resultados geraram requisitos para aprimoramento da versão final da SPP.

Palavras Chave: coletor menstrual; SPP; saúde feminina; design da informação.

\section{Abstract}

The menstrual cup is an alternative method to conventional pads or tampons that has been adopted by many Brazilians. Its use brings economic, environmental and health-related benefits in addition to women's empowerment. This article presents the design of a procedural pictorial sequence (PPS) for the use of the menstrual cup, which was developed through product rese arch and graphic analysis of similes. The design proposal was assessed by potential users and the results generated requirements for improving the final PPS.

Keywords: menstrual cup; PPS; women's health; information design.

\footnotetext{
1 Este artigo baseia-se em um projeto realizado para a disciplina Design da Informação, em 2015 do curso de bacharelado em Design da UFPR - Universidade Federal do Paraná.
} 


\section{Introdução}

O coletor menstrual tem ganhado destaque nas mídias sociais no Brasil desde 2015 e é uma alternativa sustentável aos absorventes convencionais. Existem várias comunidades na internet dedicadas às mulheres compartilharem suas experiências com o produto e tem aumentado o número de marcas que o produzem. Essa popularização do coletor no Brasil também pode ser relacionada ao crescimento da discussão feminista no país, principalmente pela internet, e aos ideais de liberdade e autonomia feminina a respeito de seus corpos (FREITAS, 2016).

A menstruação é uma experiência cheia de tabus e mitos. Nas sociedades ocidentais ela é frequentemente percebida impura e vergonhosa, as mulheres são ensinadas a silenciar sobre o assunto. Esse processo de negativar o ciclo menstrual se relaciona com a idealização do corpo feminino, ou seja, um corpo perfeito, que não sangra (RATTI, et al, 2015). Muitas mulheres têm aversão ao sangue menstrual, e às vezes não o identificam como parte natural de si, mas sim algo negativo, vergonhoso (LEAL, 1994). Desta forma, a menstruação ganha um peso além do incômodo físico ou uma questão de saúde, mas também emocional e social.

O uso do coletor também envolve outro ponto delicado: a sexualidade feminina. Muitas mulheres sentem vergonha ou culpa de tocar seus órgãos genitais, Peña (1961) aponta em seu estudo que algumas participantes de sua pesquisa resistiram a ideia de utilizar o coletor inicialmente, por ser intravaginal. Ele atribui essa resistência a fatores psicológicos relacionados a sentimentos de culpa vindos da masturbação.

Em 2017, a Anvisa passou a regulamentar a comercialização dos coletores menstruais e, entre as suas determinações, está que o produto deve trazer instruções de uso e de tamanho adequado de acordo com o fluxo (BRASIL, 2017). Nota-se, portanto, a importância da produção de materiais informativos que guiem as usuárias à utilização correta do produto e também que promovam esclarecimento sobre mitos e concepções erradas que podem gerar receio nas mulheres.

Considerando esses fatores, foi realizado o design de uma sequência pictórica de procedimento (SPP) sobre como usar o coletor menstrual. A tarefa de introduzir e retirar o coletor, apesar de simples, envolve alguns passos importantes que, se não realizados - ou realizados incorretamente - podem promover incômodos e até machucar o corpo da mulher.

Além disso, trata-se de um tema ainda visto por alguns como tabu, e de um objeto que pode ser considerado invasivo, por ser intravaginal. Assim, o design adequado de instruções de uso pode trazer segurança às usuárias e promover maior aceitação do produto. A seguir são conceituados e discutidos brevemente o coletor menstrual e SPPs, para depois apresentar a proposta desenvolvida.

\section{Coletor Menstrual}

O coletor menstrual é um método não descartável e alternativo aos absorventes convencionais de higiene menstrual. Consiste num recipiente maleável que varia entre $7 \mathrm{~cm}$ a $10 \mathrm{~cm}$ de comprimento, sendo inserido dobrado no interior do canal vaginal durante o período menstrual para coletar o sangue. Quando se abre, ocorre a formação de vácuo que faz com que o menstrual para coletar o sangue.

O coletor menstrual não é uma 'invenção' recente. Existem artigos das décadas de 1950 e 
1960 que tratam do assunto e já o apontavam como uma alternativa aos absorventes internos ou externos (LISWOOD, 1959; PEÑA, 1962). Porém, a primeira patente comercial do produto data de 1937 e foi feita por Leona Chalmers. Os exemplares que encontramos no mercado atualmente têm apenas pequenas variações do formato proposto nos anos 30 (NORTH, OLDHAM, 2011), a diferença mais importante é que na época, o coletor era feito de borracha e hoje, a maioria é produzida com silicone medicinal.

Figura 1: Exemplo de coletor menstrual dos anos 30 (à esquerda) e o coletor atual (à direita)
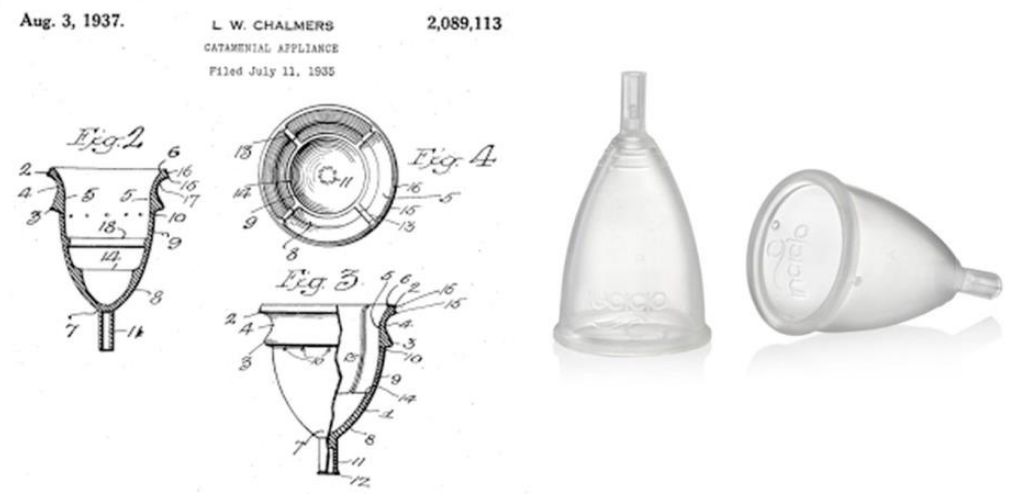

Fonte: https://goo.gl/UEALma; https://goo.gl/r76bvL. Acesso 12 mar. de 2018

Houve outras tentativas, sem sucesso, de promover o coletor menstrual nos anos 1980 (NORTH, OLDHAM, 2011). Mas, é a partir de meados de 2014 que começa a haver uma grande movimentação, principalmente da internet, sobre o produto, levando este a se popularizar no Brasil.

O uso do coletor menstrual traz diversas vantagens, tanto para a saúde da mulher quanto para o meio ambiente. Como já citado, o corpo e a sexualidade feminina são temas envoltos em tabus e preconceitos, gerando um desconhecimento da mulher a respeito de seu próprio corpo (TRINDADE; FERREIRA, 2008). O uso do coletor pode promover do autoconhecimento do corpo às mulheres, pois assim como a masturbação, exige que a mulher toque seu aparelho genital e interaja com ele.

O produto traz também algumas vantagens sob os absorventes convencionais, dentre elas a sustentabilidade. Segundo dados do fabricante nacional Korui (2018), uma pessoa pode produzir durante sua vida em média $150 \mathrm{~kg}$ de lixo apenas do descarte de absorventes. Outro fator que está a favor do coletor é econômico, a média do custo de um coletor é $\mathrm{R} \$ 80,00$ e tem durabilidade de 10 anos.

Apesar de já ter sido associado a um caso de síndrome de choque tóxico (MITCHELL et al, 2015), o coletor, quando usado corretamente, é mais higiênico. Ele evita o contato de urina e fezes com o sangue da menstruação, podendo gerar infecções, algo que ocorre nos demais absorventes (PENÃ, 1961, p.684).

Por último, destaca-se o fator da comodidade pois, de acordo com vários fabricantes (e.g., Inciclo, Korui, Fleurity), o coletor pode ser retirado até de 12 em 12 horas, enquanto a maioria dos absorventes convencionais devem ser trocados de 2 em 2 horas. Além disso George (2011) aponta em seu artigo, que após dois meses a mulher já consegue utilizar o coletor com conforto. 0 
produto transmite maior segurança para realizar certas atividades - como dança, esportes, natação, ir à praia, etc. - devido ao sistema de vendagem com vácuo. Se bem colocado, o coletor não incomoda e acaba se tornando imperceptível para a mulher (Peña, 1961). Assim, instruções como as SPPs - que comuniquem de forma eficaz como colocar, retirar e higienizar o coletor menstrual contribuem para seu uso adequado e o bem-estar da mulher.

\section{Sequência Pictórica de Procedimento (SPP)}

Sequências pictóricas de procedimento (SPPs) visam comunicar como realizar uma tarefa por meio de ilustrações que podem ser combinadas ou não com textos (SPINILLO, 2000, 2010).

Além de permitirem publicação editoriais e produtos com a técnica faça você mesmo (SPINILLO, 2010), manuais e SPPs e tem efeito benéfico para a indústria, diminuindo custos com produção e manutenção de produtos (RICHARDS, 1998). No âmbito social, as sequências pictóricas de procedimento exercem o papel principal como forma de comunicação para a população com baixo grau de escolaridade, especialmente em áreas relacionadas à saúde, como contracepção e higiene (DYSON e SPINILLO, 2001).

Spinillo (2000), propõe um modelo de análise gráfico-informacional da representação de SPPs considerando: apresentação do texto e legenda (texto-corrido e/ou rótulo); disposição da sequência (e.g., horizontal, vertical, oblíqua, circular); orientadores de leitura (e.g., números, setas, letras); elementos de separação visual (e.g., espaço, linhas, bordas); elementos simbólico (e.g., setas, barra diagonal); elementos enfáticos (e.g., lupa, cor); estilo da ilustração (e.g., fotográfico, desenho, esquemático e/ou sombra), representação da figura (e.g., ilustrações parciais e/ou completas). A figura a seguir (Tabela 1) apresenta o modelo descritivo de SPPs que foi empregado no desenvolvimento da SPP proposta para o coletor menstrual.

Tabela 1: Modelo descritivo de SPPs (Spinillo, 2000).

\begin{tabular}{|c|c|c|c|c|c|c|c|c|c|c|c|c|c|}
\hline & \multicolumn{13}{|c|}{ AMOSTRAS } \\
\hline & descrição & 1 & 2 & 3 & 4 & 5 & 6 & 7 & 8 & 9 & 10 & oc. & TOTAL \\
\hline \multirow{2}{*}{ apresentação do texto } & legenda & & & & & & & & & & & & \\
\hline & título & & & & & & & & & & & & \\
\hline \multirow{2}{*}{ disposição da sequência } & horizontal & & & & & & & & & & & & \\
\hline & vertical & & & & & & & & & & & & \\
\hline \multirow{3}{*}{ orientadores de leitura } & números & & & & & & & & & & & & \\
\hline & setas & & & & & & & & & & & & \\
\hline & letras & & & & & & & & & & & & \\
\hline \multirow{4}{*}{$\begin{array}{l}\text { elementos de } \\
\text { separação visual }\end{array}$} & espaço & & & & & & & & & & & & \\
\hline & linhas & & & & & & & & & & & & \\
\hline & bordas & & & & & & & & & & & & \\
\hline & boxes & & & & & & & & & & & & \\
\hline \multirow{4}{*}{ elementos simbólicos } & setas & & & & & & & & & & & & \\
\hline & barras & & & & & & & & & & & & \\
\hline & pontilhado & & & & & & & & & & & & \\
\hline & vista seccional & & & & & & & & & & & & \\
\hline \multirow{2}{*}{ elementos enfáticos } & forma & & & & & & & & & & & & \\
\hline & cor & & & & & & & & & & & & \\
\hline \multirow{4}{*}{ estilo da ilustração } & fotográfico & & & & & & & & & & & & \\
\hline & desenho & & & & & & & & & & & & \\
\hline & esquemático & & & & & & & & & & & & \\
\hline & sombra & & & & & & & & & & & & \\
\hline \multirow{3}{*}{ representação da figura } & parcial & & & & & & & & & & & & \\
\hline & completa & & & & & & & & & & & & \\
\hline & TOTAL & 8 & 6 & 9 & 10 & 7 & 9 & 6 & 5 & 9 & 7 & & \\
\hline
\end{tabular}

Fonte: Spinillo, 2000. 


\section{Estudo sobre o coletor menstrual: Análise de similares}

Foi realizado um estudo analítico de similares sobre instruções de uso do coletor menstrual a fim de identificar características da representação gráfica do produto passíveis de serem consideradas na proposta de SPP. Este estudo também constou de avaliação da representação gráfica das instruções analisadas para identificar deficiências que devem ser evitadas em nossa proposta.

\subsection{Amostra}

A amostra constou de 10 SPPs sobre o uso do coletor menstrual (Figura 2) selecionadas de sites e blogs sobre saúde da mulher e de sites de fabricantes, disponíveis na internet.

Figura 2: Amostras analisadas.

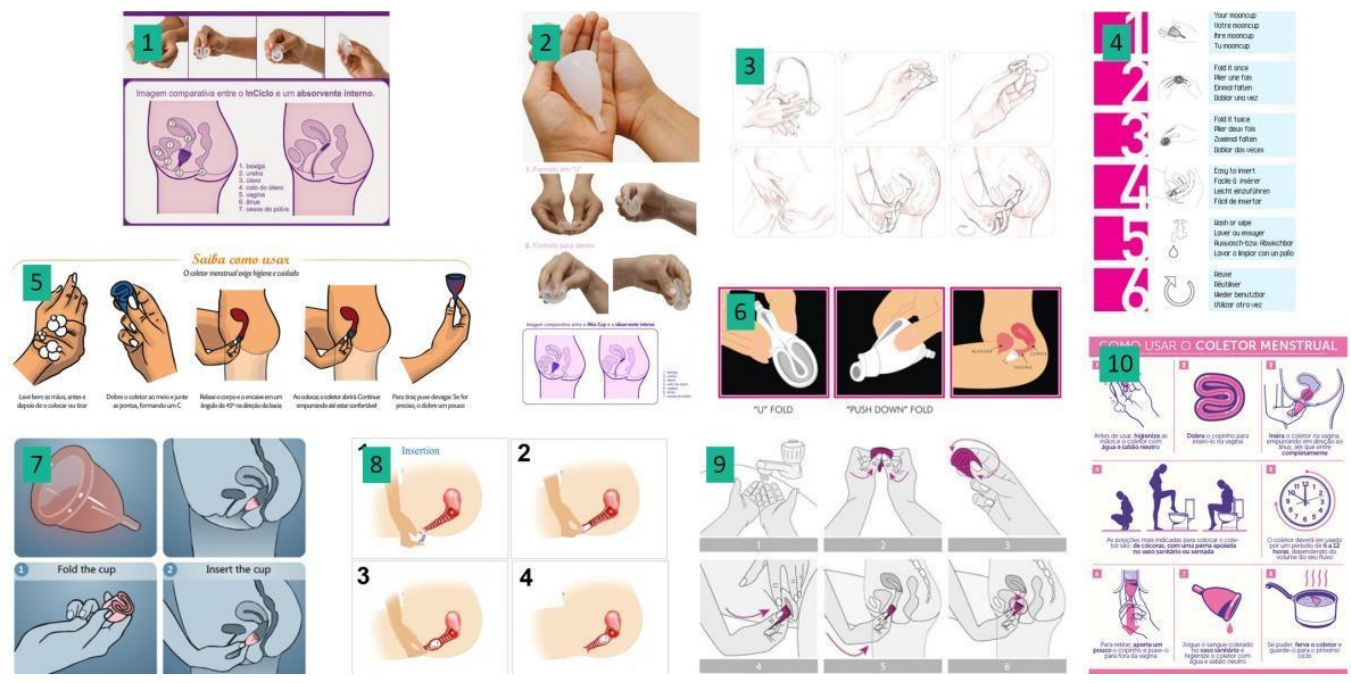

Fonte:

\begin{tabular}{|l|l|}
\hline [1] https://goo.gl/d8hMFd Acesso 18 set. de 2015 & [2] https://goo.gl/ZtZZGW Acesso 18 set. de 2015 \\
\hline [3] https://goo.gl/Hx2GR9 Acesso 18 set. de 2015 & [4] https://goo.gl/Qvno9r Acesso 18 set. de 2015 \\
\hline [5] https://goo.gl/Hvmjhq Acesso 18 set. de 2015 & [6] https://goo.gl/TjiR9N Acesso 18 set. de 2015 \\
\hline [7] https://goo.gl/29UomR Acesso 18 set. de 2015 & [8] https://goo.gl/29UomR Acesso 18 set. de 2015 \\
\hline [9] https://goo.gl/HAxug5 Acesso 18 set. de 2015 & [10] https://goo.gl/336AKF Acesso 18 set. de 2015 \\
\hline
\end{tabular}

\subsection{Instrumento de análise}

As amostras foram submetidas a análise através do modelo de análise gráfica descritiva proposto por Spinillo (2000). Os resultados foram compilados em tabelas de síntese com ocorrências de cada variável. Foi realizada também uma avaliação com julgamento de valor (bom, razoável, ruim) da qualidade gráfico-informacional da representação da tarefa de uso do coletor em cada SPP. 


\subsection{Resultados da análise}

A maioria das SPPs da amostra apresenta imagem e texto com disposição horizontal da sequência. Nota-se bastante variedade de elementos de separação visual; a seta e a cor são os elementos simbólico e enfático mais empregados, respectivamente. O desenho é o estilo da ilustração predominante. Em unanimidade as SPPs apresentam a representação da figura de maneira parcial, sendo que apenas três contam também com a representação completa em algum quadro. A Tabela 2 a seguir mostra a síntese dos resultados da análise gráfica das SPPs de acordo com o modelo de Spinillo (2000). As colunas apresentam a SPP avaliada (de acordo com a numeração da Figura 3) e as linhas apresentam os elementos que foram analisados em cada amostra. As cores verde, amarela e vermelha representam indicadores de qualidade sendo bom, razoável e ruim, respectivamente.

Tabela 2: Síntese da análise - Modelo adaptado de Spinillo (2000).

\begin{tabular}{|c|c|c|c|c|c|c|c|c|c|c|c|c|c|c|c|}
\hline & \multicolumn{15}{|c|}{ AMOSTRAS } \\
\hline & descrição & 1 & 2 & 3 & 4 & 5 & 6 & 7 & 8 & 9 & 10 & oc. & \multicolumn{3}{|c|}{ TOTAL } \\
\hline \multirow{2}{*}{ apresentação do texto } & legenda & & & & & & & & & & & 7 & \multirow{2}{*}{5} & & \\
\hline & título & & & & & & & & & & & 1 & & & \\
\hline \multirow{2}{*}{ disposição da sequência } & horizontal & & & & & & & & & & & 6 & \multirow{2}{*}{3} & \multirow{2}{*}{\multicolumn{2}{|c|}{1}} \\
\hline & vertical & & & & & & & & & & & 2 & & & \\
\hline \multirow{3}{*}{ orientadores de leitura } & números & & & & & & & & & & & 8 & \multirow{3}{*}{2} & & \\
\hline & setas & & & & & & & & & & & 0 & & & 1 \\
\hline & letras & & & & & & & & & & & 0 & & & \\
\hline \multirow{4}{*}{$\begin{array}{l}\text { elementos de } \\
\text { separação visual }\end{array}$} & espaço & & & & & & & & & & & 4 & & & \\
\hline & linhas & & & & & & & & & & & 3 & & & \\
\hline & bordas & & & & & & & & & & & 2 & & & \\
\hline & boxes & & & & & & & & & & & 4 & & & \\
\hline \multirow{4}{*}{ elementos simbólicos } & setas & & & & & & & & & & & 5 & & & \\
\hline & barras & & & & & & & & & & & 0 & & & 2 \\
\hline & pontilhado & & & & & & & & & & & 1 & & & \\
\hline & vista seccional & & & & & & & & & & & 2 & & & \\
\hline \multirow{2}{*}{ elementos enfáticos } & forma & & & & & & & & & & & 0 & & \multirow{2}{*}{\multicolumn{2}{|c|}{0}} \\
\hline & cor & & & & & & & & & & & 7 & & & \\
\hline \multirow{4}{*}{ estilo da ilustração } & fotográfico & & & & & & & & & & & 2 & \multirow{4}{*}{0} & \multirow{4}{*}{\multicolumn{2}{|c|}{2}} \\
\hline & desenho & & & & & & & & & & & 9 & & & \\
\hline & esquemático & & & & & & & & & & & 0 & & & \\
\hline & sombra & & & & & & & & & & & 0 & & & \\
\hline \multirow{3}{*}{ representação da figura } & parcial & & & & & & & & & & & 10 & \multirow{2}{*}{1} & & 1 \\
\hline & completa & & & & & & & & & & & 3 & & & \\
\hline & TOTAL & 8 & 6 & 9 & 10 & 7 & 9 & 6 & 5 & 9 & 7 & 103 & 24 & 42 & 9 \\
\hline
\end{tabular}

Fonte: As autoras, 2018.

Como pontos positivos (avaliação boa), a aplicação da cor como elemento enfático na maior parte das SPPs, assim como o uso de texto como legenda, com boa legibilidade. Porém, foram considerados como principais problemas (avaliação ruim) aspectos relacionados à ilustração, principalmente quanto ao estilo e a representação da figura. Constatou-se também carência de elementos simbólicos que poderiam ajudar a compreender melhor as ações a serem realizadas para o uso do coletor menstrual.

Muitas SPPs tiveram avaliação regular quanto ao estilo da ilustração (sendo a maior parte 
com desenhos) e a representação da figura parcial, que aparece em toda a amostragem. Isso se deve ao fato de que muitas amostras apresentavam desenhos simplificados (Amostra 5) ou complexos (Amostra 8) demais, ou ainda, alguns anatomicamente incorretos, seja quanto aos órgãos ou a posição do coletor (Amostra 10).

Por exemplo, a SPP 10 (Figura 3) apresenta algumas deficiências como, não possuir um título que ajude a contextualizar a usuária (A). Além disso, não estão presentes vários elementos (enfáticos ou simbólicos) que poderiam ajudar na compreensão da tarefa, tais como setas, cores ou formas. A vista seccional, apesar de presente, é mal executada misturando dois estilos de ilustração (B), mostrando apenas algumas partes do corpo (C) e é uma representação pouco fiel a anatomia feminina. $O$ coletor também se encontra posicionado de forma incorreta, logo abaixo do colo do útero, quando deveria ser logo após a entrada do canal vaginal (D). A SSP não dispõe de legendas para explicar os passos e não instruí como dobrar o coletor ou como retirá-lo.

Figura 3: Exemplo de deficiências identificadas na amostra analisada quanto a Amostra 10.

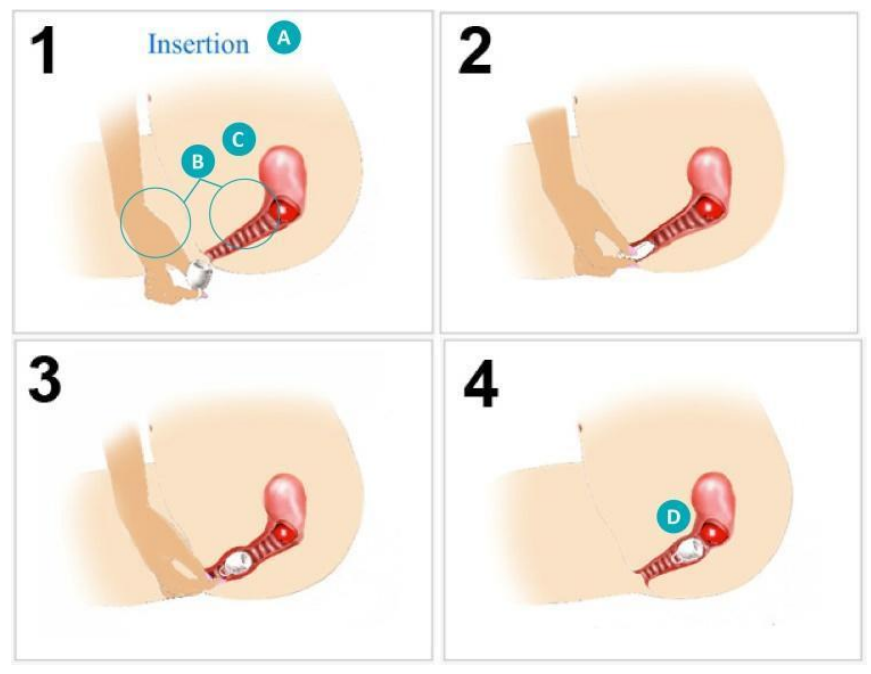

Fonte: as autoras, 2018.

\section{Proposta de design de SPP para uso do coletor menstrual}

Baseando-se nos resultados do estudo analítico e na literatura foram estabelecidos os seguintes requisitos para o desenvolvimento da SPP:

- Incluir título na SPP, para ao ser vista isoladamente, ela ainda apresente contexto;

- Destacar a orientação da sequência de leitura. Os números apresentam uma boa solução. Porém, os passos precisam ser verificados para que façam sentido e a tarefa fique completa;

- Incluir elementos simbólicos para ajudar a compreensão das ações. Porém, fazer isso com cautela e observando o contexto de uso;

- Conferir clareza à ilustração porque se trata de uma aplicação em uma área de pouca visibilidade para a usuária; 
- Usar estilo desenho para exemplificar de maneira fiel as proporções entre o coletor, partes do corpo e o ambiente da realização da tarefa;

- Usar representação mais próxima da qual a usuária terá durante a realização da tarefa. A vista genital seccional é importante, porém não é suficiente. Isto, principalmente quando direcionado a mulheres com baixa escolaridade ou com pouco conhecimento dos seus corpos, pois podem não conhecer os órgãos internos do corpo.

- Destacar na ilustração a "pega" do coletor, que é fundamental para a inserção correta.

Considerando os requisitos, decidiu-se que a representação dos procedimentos seria realizada como ocorre na visão da usuária em situação real. Isto objetivou aumentar sua segurança ao realizá-los, e assim solucionar possíveis dúvidas quanto a colocação do coletor. Foi adicionado também informação de como não deve ser realizado alguns passos da tarefa para evitar erros que prejudiquem o uso do coletor menstrual. Levantou-se a questão se é necessário adicionar na SPP os passos de limpeza e esterilização do coletor, deixando esta questão para ser respondida na avaliação da SPP pelas usuárias. A Figura 4 mostra a proposta de SPP desenvolvida para as usuárias do coletor menstrual.

Figura 4: Proposta de SPP.
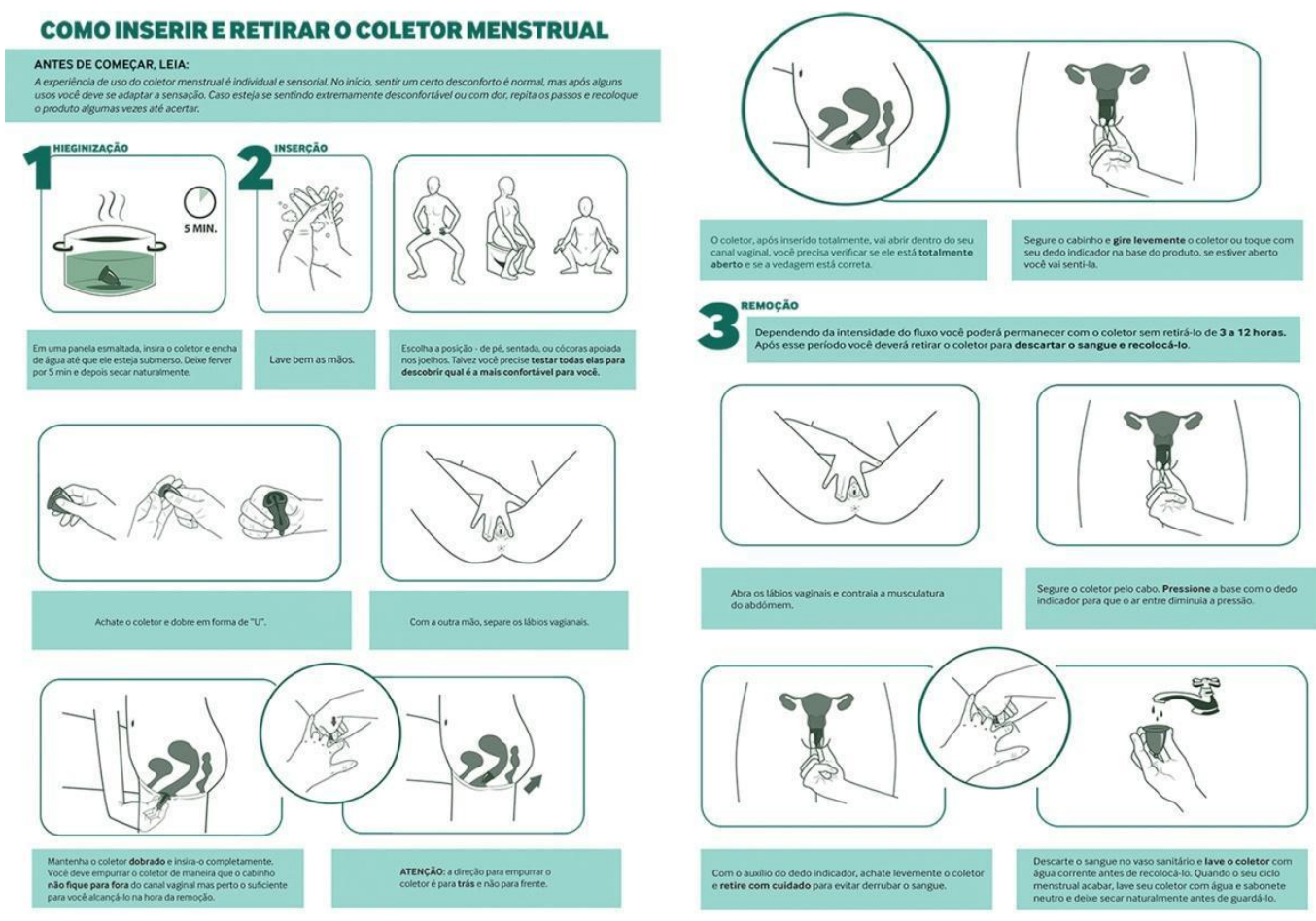

Fonte: As autoras, 2018. Disponível em maior resolução: https://imgur.com/5Ry0JeA

\section{Avaliação da proposta}

\subsection{Método: material, participantes e procedimentos}


As técnicas utilizadas na avaliação foram: a observação das usuárias simulando o uso do coletor menstrual, a verbalização durante a tarefa simulada e questionário (adaptado de Amorim, 2017).

Figura 5: Material utilizado na avaliação.

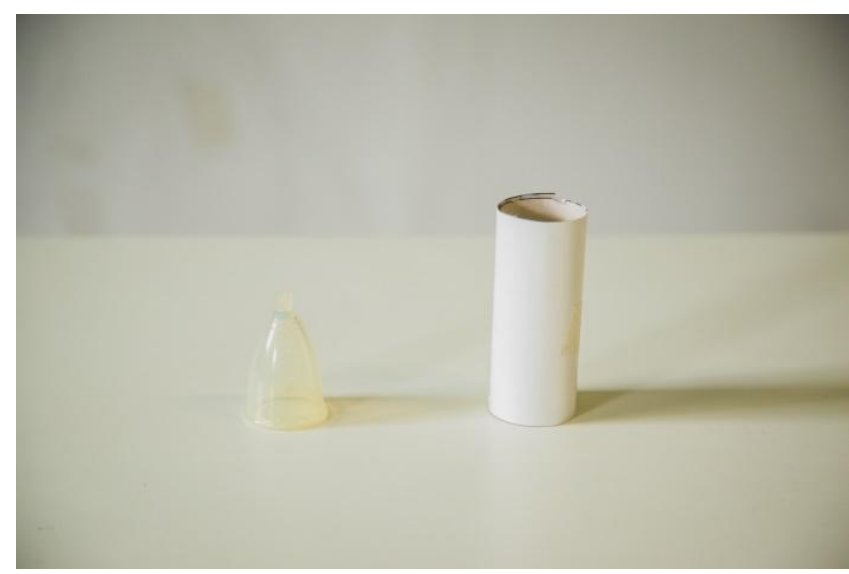

Fonte: As autoras, 2018

Dez voluntárias estudantes do sexo feminino, entre 17 e 23 anos, sem experiência de uso do coletor participaram da avaliação. O material constou da SPP proposta em formato A4, coletor menstrual da marca InCiclo e um pequeno rolo vazado feito de papelão representando o canal vaginal (Figura 5).

Pediu-se que as usuárias lessem a SPP quantas vezes quisessem e tentassem realizar a tarefa verbalizando os passos tomados, podendo consultar o material durante a realização da tarefa. Em seguida foi realizada entrevista individual com perguntas abertas, fechadas e de escala. A avaliação foi registrada por vídeo.

\subsection{Resultados da avaliação}

A tarefa foi realizada completamente por todas as participantes, porém a maioria cometeu erros $(n=7)$. Sendo eles: inserir ou retirar o coletor aberto $(n=6)$ ou deixar o cabo para fora da vagina $(n=2)$.

Quando solicitadas a descrever os passos da tarefa, apenas 2 das entrevistadas esqueceram algum passo. Ao serem indagadas qual parte (imagens ou texto) mais ajudou na compreensão do material, todas as voluntárias responderam que ambos tiveram a mesma importância. Quanto à dificuldade na compreensão de algum passo, 2 voluntárias tiveram dificuldade em entender a direção em que se empurra o coletor e outras 2, dificuldade no entendimento da retirada e pega do coletor.

Todas as participantes concordaram ou concordaram parcialmente que a experiência de interação com a SPP foi satisfatória, a apresentação do conteúdo coerente, e a quantidade de informações adequadas. A maioria das entrevistadas $(n=9)$ discordou ou discordou parcialmente que a SPP parece complicada à primeira vista ou que ficaram confusas com a sequência dos passos. Quando questionadas se conseguiram entender os passos da tarefa com a SPP, 7 das voluntárias concordaram ou concordaram parcialmente, bem como a maioria $(n=8)$ também concordaram ou concordaram parcialmente que a relação entre conteúdo de texto e imagem foram explicativos. Em se tratando do conteúdo da SPP ser confuso, 7 das entrevistadas 
discordaram ou discordaram totalmente. As imagens da SPP foram consideradas simples e claras para 9 das participantes da avaliação.

Durante a avaliação pode-se observar o aspecto sensorial da tarefa e como ela pode ser afetada pela distância da experiência real e da simulação com o protótipo. Foi possível também perceber o tabu relacionado ao corpo feminino devido dificuldade ou incômodo de algumas participantes ao falarem palavras como vagina e menstruação.

Mesmo num protótipo distante do original, as usuárias refizeram a tarefa duas ou três vezes, o que indica complexidade e também que é necessário praticar e passar por um processo de adaptação para atingir bons resultados. Percebeu-se que a divisão numerada por bloco de tarefa é confusa, pois a usuária tende a enxergar como passos imediatamente sequenciais.

\subsection{Requisitos oriundos da avaliação}

Após a avaliação gerou-se alguns requisitos baseados nas dificuldades e comentários feitos pelas usuárias, os quais listam-se abaixo:

- (A) Adicionar mais informações sobre a fisiologia feminina, para tentar diminuir a falta do entendimento biológico das mulheres a respeito de seu corpo;

- (B) Acrescentar informações sobre o tamanho do coletor, pois se a SPP for visualizada anteriormente ou fora do contexto de instruções de uso é uma informação relevante para usuária tomar decisão correta de compra;

- (C) Enumerar os passos para deixar a sequência de leitura mais clara;

- (D) Na etapa de escolher a melhor posição para fazer a inserção do coletor, identificar as opções de posição como a, b ou c, para evitar que pudesse ser lido como uma sequência de passos;

- (E) Enfatizar os passos na dobra do coletor ao numerar a sequência;

- (F) Alterar a disposição do título e das legendas dos passos, tirando-as do interior do box e reposicionando para perto das imagens, para maior legibilidade;

- (G) Adaptar o conteúdo para um tom mais didático;

- (H) Incluir o passo como higienizar o coletor no fim do ciclo.

\section{Versão final}

A partir destes requisitos fez-se as adaptações propostas (que estão sinalizadas na Figura 6 de acordo com a lista dos requisitos já citada), gerando assim uma nova proposta de design. Esta versão final é mais completa em termos de conteúdo e teve seu layout redefinido para melhor atender às dúvidas das usuárias durante a avaliação. 
Figura 6: Versão final - refinada pós-avaliação.

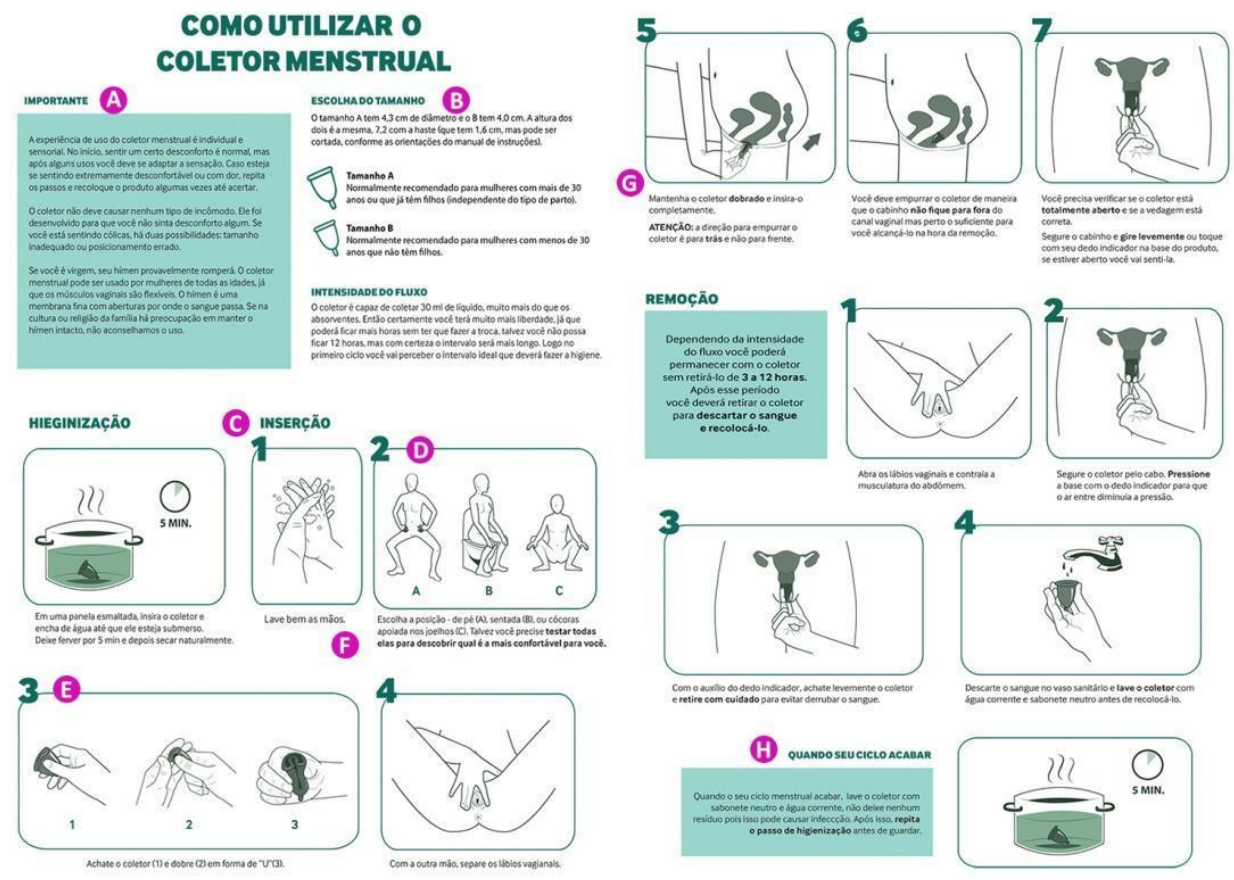

Fonte: As autoras, 2018. Disponível em maior resolução: https://imgur.com/AVw2lij

\section{Conclusão}

Neste artigo revisou-se bibliografia sobre SPP, sua função social e elementos, bem como o sobre o coletor menstrual. Foram analisadas amostras de SPP encontradas na internet a respeito do uso do coletor e com base no estudo, propôs-se e validou-se de uma SPP, cujo objetivo é sanar deficiências encontradas nas amostras e acrescentar elementos que auxiliassem as usuárias, a partir das suas dificuldades expressas na avaliação.

Durante a execução do projeto, pode-se observar que o uso do coletor menstrual demanda um processo de adaptação muito particular de cada indivíduo, e nisto reside a dificuldade em produzir uma SPP que seja totalmente efetiva em promover instruções que garantam a realização completa da tarefa sem erros ou dificuldades.

Fatores outrora citados como o tabu quanto às mulheres tocarem o próprio corpo, a menstruação, idealização e medicalização do corpo feminino são questões culturais que tornam o uso do coletor ainda mais complexo. Portanto, destaca-se a importância de instruções de uso bem pensadas e desenvolvidas com atentamente a estas questões.

A SPP produzida teve bons resultados na avaliação, e foi ainda refinada pelos requisitos gerados a partir dela; nisto acredita-se que cumpre os objetivos de propor uma solução academicamente embasada e funcional para as instruções de uso do coletor menstrual. No entanto, aponta-se que a solução visual proposta na versão final da SPP ainda pode precisar de muitos refinamentos e deve passar por outros processos avaliativos e validativos, que sejam feitos em condições melhores para entender quais dados verbais e visuais realmente auxiliam na realização da tarefa.

Por fim, espera-se que este trabalho gere reflexões e discussões a respeito do 
desenvolvimento de sequências pictóricas de procedimento para produtos femininos ligados à sexualidade e saúde, que promovem maior autonomia às mulheres em relação aos seus corpos.

\section{Referências}

AMORIM L. G. Variáveis gráficas descritivas de estilo de ilustração em sequências pictóricas de procedimentos para bulas de medicamentos. Tese de mestrado não publicada. 2017. Departamento de Design. Universidade Federal do Paraná.

BRASIL. Resolução no 142, de 2017. Órgão emissor: ANVISA - Agência Nacional de Vigilância Sanitária. Disponível em: <http://portal.anvisa.gov.br/legislacao\#/visualizar/343900>. Acesso em: $21 \mathrm{fev} .2018$.

FLEURITY. Vantagens. Disponível em: <http://fleurity.com.br/\#vantagens> Acesso 15 fev. 2018.

FREITAS, Ana. $\mathbf{O}$ que o coletor menstrual tem a ver com tabus femininos em relação ao próprio corpo, 2016. Disponível em: <https://www.nexojornal.com.br/expresso/2016/04/06/O-que-ocoletor-menstrual-tem-a-ver-com-tabus-femininos-em-rela\%C3\%A7\%C3\%A3o-ao-pr\%C3\%B3priocorpo> Acesso em 27 fev. 2018.

INCICLO. Vantagens. Disponível em: <https://www.inciclo.com.br/pagina/vantagens.html> Acesso em 15 fev. 2018.

KARNAKY, KARL JOHN M.D., F.A.C.O.G. Internal Menstrual Protection with the Rubber Menstrual Cup.

<http://journals.Iww.com/greenjournal/Citation/1962/05000/Internal_Menstrual_Protection_wit h_the_Rubber.20.aspx> Acesso em 15 fev. 2018.

KORUI. Coletor Menstrual. Disponível em: <http://www.korui.com.br/coletor-menstrual/> Acesso 15 fev. 2018.

KORUI. Quanto custa a menstruação? Disponível em: <http://www.korui.com.br/quanto-custa-amenstruacao/>. Acesso em: 27 fev. 2018.

LEAL, O.F. Sangue, fertilidade e práticas contraceptivas. In: ALVES, PC., and MINAYO, MCS., orgs. Saúde e doença: um olhar antropológico [online]. Rio de Janeiro: Editora FIOCRUZ, 1994. Disponível em: <http://books.scielo.org/id/tdj4g/pdf/alves-9788575412763-11.pdf>. Acesso em: 27 fev. 2018.

LISWOOD, REBECCA M.D. Internal Menstrual Protection: Use of a safe and sanitary menstrual cup.

Disponível

em

<http://journals.Iww.com/greenjournal/Citation/1959/05000/Internal_Menstrual_Protection_Us e_of_a_safe_and.3.aspx> Acesso 15 fev. 2018.

MITCHELL, A. M.; Bisch, S.; ARNTFIELD, S.; HOSSEINI - MOGHADDAM, M. S. A Confirmed Case of Toxic Shock Syndrome Associated with the Use of a Menstrual Cup. Canadian Journal of Infectious Diseases and Medical Microbiology, vol. 26, no. 4, pp. 218-220, 2015. Disponível em: <https://www.hindawi.com/journals/cjidmm/2015/560959/abs/> Acesso em 28 fev. 2018.

North, B. B., \& Oldham, M. J. (2011). Preclinical, clinical, and over-the-counter postmarketing experience with a new vaginal cup: menstrual collection. Journal of women's health (2002), 20(2), 303-11. 
PEÑA, EDUARDO F. M.D., F.A.C.O.G. Menstrual Protection: Advantages of the Menstrual Cup. Disponível

<http://journals.Iww.com/greenjournal/Citation/1962/05000/Menstrual_Protection_Advantages _of_the_Menstrual.19.aspx> Acesso $15 \mathrm{fev} .2018$.

RATTI,C. R.; AZZELLINI, E. C.;BARRENSE,H.; Grohmann, R. O Tabu da Menstruação Reforçado pelas

Propagandas de Absorvente. Disponível em
<http://portalintercom.org.br/anais/nacional2015/resumos/R10-0436-1.pdf> Acesso 15 fev. 2018.

RICHARDS,C. Getting the picture: diagram design and the information revolution. Disponível em: <http://www.ingentaconnect.com/content/jbp/idj/1998/00000009/f0020002/art00001?crawler=t rue> Acesso 01 mar. 2018.

SPINILLO, C. G. An analytical approach to procedural pictorial sequences. Tese PhD não publicada. 2000. Department of Typography \& Graphic Communication, The University of Reading. Reading.

SPINILLO, C. G. Diseño de información de instrucciones visuales. México: CEAD, 2010.

SPINILLO, C. G.; DYSON, M. C. An exploratory study of reading procedural pictorial sequences. In: Information Design Journal 10(2), 154-168. Amsterdam: John Benjamins Publishing Company. 2001. Disponível em <https://benjamins.com/\#catalog/journals/idj.10.2.13spi/details> Acesso 01 mar. 2018.

TRINDADE, W.; FERREIRA, M. de Assunção. Sexualidade feminina: questões do cotidiano das mulheres. Texto \& Contexto Enfermagem, 17 (3), 417-426. Disponível em <http://www.redalyc.org/articulo.oa?id=71417304> Acesso em: 27 fev. 2018. 